\title{
PRÁTICAS PEDAGÓGICAS PARA O ENSINO DE FRAÇÕES OBJETIVANDO A INTRODUÇÃO À ÁLGEBRA
}

Tese de Doutorado

Tese apresentada como requisito parcial para obtenção do título de Doutor pelo Programa de PósGraduação em Educação da PUC-Rio.

Orientador: Gilda de La Rocque Palis

Co-orientador: Maria Apparecida Campos Mamede Neves

Volume I

Rio de Janeiro

Maio de 2008 
Neide da Fonseca Parracho Sant'Anna

\section{Práticas Pedagógicas para o ensino de Frações Objetivando a Introdução à Álgebra}

Tese apresentada como requisito parcial para obtenção do título de Doutor pelo Programa de Pós-Graduação em Educação da PUC-Rio. Aprovada pela Comissão Examinadora abaixo assinada.

Profa. Gilda de La Rocque Palis Orientadora PUC-Rio

Prof ${ }^{a}$. Maria Apparecida Campos Mamede Neves Co-orientadora PUC-Rio

Prof. Celso Braga Wilmer PUC-Rio

Prof ${ }^{a}$. Elizabeth Belfort da Silva Moren UFRJ

Profa . Lílian Nasser

UFRJ

Profo Paulo Fernando Carneiro de Andrade Coordenador (a) Setorial do Centro de Teologia e Ciências Humanas PUC - Rio

Rio de Janeiro, 16 de maio de 2008. 
Todos os direitos reservados. É proibida a reprodução total ou parcial do trabalho sem autorização da universidade, da autora e do orientador.

\section{Neide da Fonseca Parracho Sant'Anna}

Graduou-se em Matemática na UFRJ. Ingressou no curso de pós-graduação em Matemática na PUC-Rio, obtendo o título de mestre em 2001. Tem experiência na docência de Matemática no ensino básico e no ensino superior. Participa de Projeto de Pesquisa em Educação Matemática, bem como possui trabalhos publicados nesta área.

Ficha catalográfica

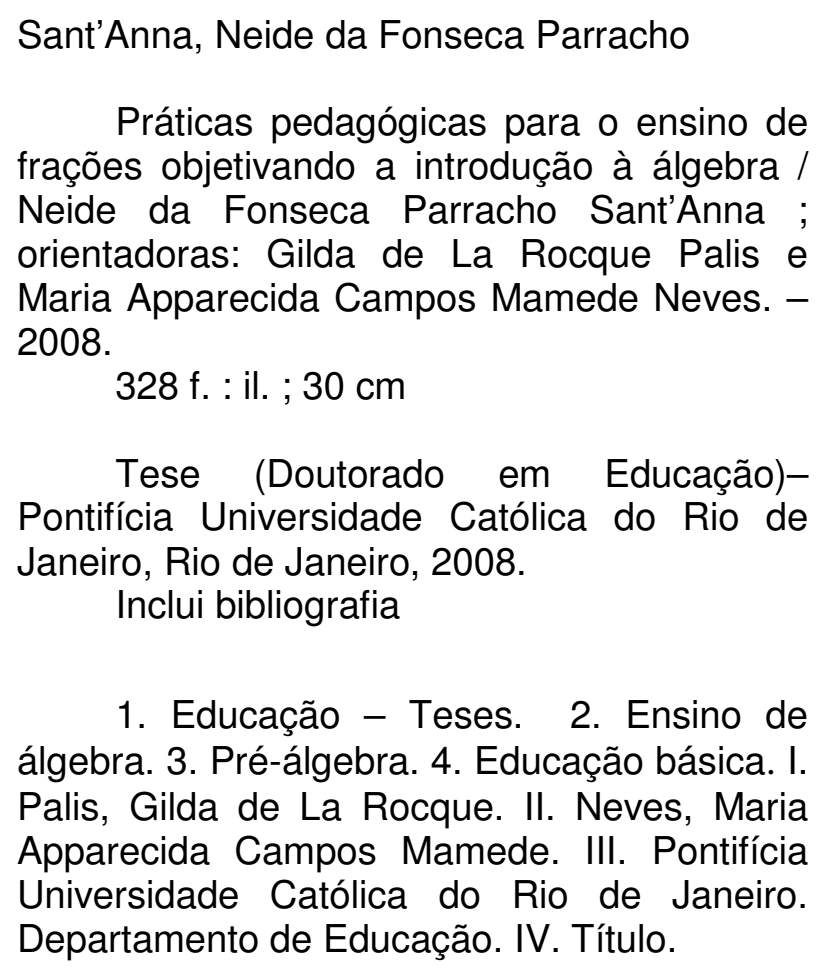

1. Educação - Teses. 2. Ensino de álgebra. 3. Pré-álgebra. 4. Educação básica. I. Palis, Gilda de La Rocque. II. Neves, Maria Apparecida Campos Mamede. III. Pontifícia Universidade Católica do Rio de Janeiro. Departamento de Educação. IV. Título.

CDD: 370 
À minha família, Annibal, João Paulo, Leonardo Augusto e Ana Luiza, Julia e Lucas, esposo, filhos, nora e netos, pelo apoio incondicional em todos os momentos.

Ao meu pai Luiz e à minha mãe Dalva em memória.

À minha irmã Wanda, pela ajuda silenciosa, em tantos momentos com quem venho compartilhando as etapas vencidas e à amiga Maria Ciema, pelas sábias palavras de conforto e estímulo. 
Ao meu Deus, autor e consumador da minha vitória e que me ensinou, passo a passo:

A considerar atentamente na lei perfeita, lei da liberdade e nela perseverar, não sendo ouvinte negligente, mas operosa praticante, tornandome bem-aventurada no que realizo.

(Tiago 1:25)

Obrigada meu Deus. 


\section{Agradecimentos}

À querida amiga e orientadora Professora-doutora Maria Apparecida C. Mamede Neve, sempre presente e atenta em todos os momentos, principalmente nos mais difíceis dessa caminhada.

À amiga e orientadora Professora-doutora Gilda de La Roque Palis, fornecendo subsídios sem os quais não teríamos chegado às conclusões tão almejadas.

À Professora-doutora Elizabeth Belfort da S. Moren pelo incentivo e sugestões.

À amiga Professora-doutora Lilian Nasser pela orientação, carinho, atenção, apoio e confiança ao longo desse percurso.

Ao Professor-doutor Celso B. Wilmer pelo apoio e confiança.

Ao Professor-doutor João Bosco Pitombeira Fernandes de Carvalho pela compreensão inestimável.

À amiga Professora-doutora Flavia Soares, sempre pronta a dar seu valioso e escasso tempo para colaborar diante das dificuldades advindas nesta caminhada.

À amiga Professora e mestre Mercedes Mercy, pela ajuda e confiança desde o início desse curso. 
Aos integrantes do Projeto Fundão - UFRJ, em particular a querida Professora Emérita do Instituto de Matemática, Maria Laura Mouzinho Leite Lopes pelo carinho e constante incentivo.

À amiga Professora Vera Maria Ferreira Rodrigues, Secretária de Ensino, hoje Diretora Geral do Colégio Pedro II, sempre presente e atenta às dificuldades características de uma Intuição de Ensino do porte do Colégio Pedro II.

À direção da Unidade Escolar Centro, Prof. Flavio de Oliveira Norte, a equipe de Matemática, em particular à Professora Ana Lúcia, Professora Ana Patrícia e ao Professor Francisco Roberto durante todo processo.

A toda equipe da Secretaria da Unidade Escolar Centro, pela constante presteza em fornecer dados necessários ao desenvolvimento da pesquisa.

A equipe do Setor de Supervisão e Orientação Pedagógica - SESOP, pela ajuda inestimável junto aos alunos e pais ao longo deste trabalho.

Ao Professor Geraldo Pinto Vieira, Chefe do Departamento de História do Colégio Pedro II, no período de 1985 a 1990, que com sua incansável dedicação possibilitou-me ter ao alcance um material de difícil acervo.

À Professora-doutora Vera Lucia Cabana Q. Andrade Coordenadora do Núcleo de Documentação e Memória - NUDOM do Colégio Pedro II e, em particular, a Bibliotecária Elizabeth Monteiro da Silva.

A todos que contribuíram direta e indiretamente na realização desse trabalho.... muito obrigada. 


\section{Resumo}

Sant'Anna, Neide da Fonseca Parracho; Palis, Gilda de La Rocque . Práticas Pedagógicas para o ensino de Frações objetivando a introdução à Álgebra. Rio de Janeiro, 2008. 328p. Tese de Doutorado Departamento de Educação, Pontifícia Universidade Católica do Rio de Janeiro.

A idéia central desta tese foi trabalhar o conceito de fração, identificando a fração como número e representando esse número na reta numérica, tendo como base as recomendações e experiências realizadas por Kathleen Hart, e principalmente Hung-Hsi $\mathrm{Wu}$. Um conjunto de atividades foi desenvolvido, constituindo uma proposta de ensino de frações, posta em prática em turmas do sétimo ano e oitavo ano do Colégio Pedro II durante os anos letivos de 2006 e 2007. Parte substancial da tese é dedicada à descrição dos procedimentos metodológicos desenvolvidos para a aplicação dos princípios teóricos defendidos e de aspectos da implementação desses procedimentos em sala de aula. Grande número de exemplos das atividades realizadas é apresentado, dando-se destaque às resposta dos alunos às mesmas. $\mathrm{O}$ acompanhamento da evolução dos alunos é amplamente documentado. Os resultados são avaliados tanto do ponto do vista global quanto do ponto de vista de grupos diferenciados de alunos em diferentes níveis de qualificação prévia. $\mathrm{O}$ encaminhar de todo o trabalho investigativo leva a duas conclusões essenciais: a familiarização com o campo algébrico é alcançada com mais facilidade quando o conceito de fração é trabalhado na forma proposta; o envolvimento com as atividades e a compreensão pelos alunos da construção que estavam realizando em relação aos conceitos propostos devolvem o interesse das crianças pela aprendizagem da Matemática, fundamental para o êxito de qualquer proposta pedagógica.

\section{Palavras-chave}

Ensino de Frações; Pré-álgebra; Educação Básica. 


\section{Abstract}

Sant'Anna, Neide da Fonseca Parracho; Palis, Gilda de La Rocque. "Pedagogical practices for teaching fractions aiming at the introduction to algebra". Rio de Janeiro, 2008. 328 p. Tese de Doutorado Departamento de Educação, Pontifícia Universidade Católica do Rio de Janeiro.

The main idea of this thesis was to work on the concept of fraction, identifying the fraction as a number and representing it in the line, taking as basis the recommendations and experiments of Kathleen Hart, and, mainly Hung-Hsi $\mathrm{Wu}$. A set of activities was developed, generating a proposal for teaching fractions, led to practice in classes of students of $7^{\text {th }}$ and $8^{\text {th }}$ grade of Colegio Pedro II during the school years of 2006 and 2007. A substantial part of the thesis is devoted to the description of the methodological procedures developed for the implementation of the theoretical principles defended and of aspects of the implementation of these procedures in the classroom. Large number of examples is given of the activities performed, emphasis being given to the response of the students. The monitoring of the progress of the students is widely documented. The results are evaluated from the global point of view and considering distinct groups of students at different levels of prior qualification. The development of all the research work led essentially to two conclusions: the familiarization with the algebraic field is more easily reached when the concept of fraction is dealt in the proposed way; the involvement of the students with the activities and their understanding of the construction that they were doing with the concepts proposed returned them the interest for learning mathematics, the key to the success of any educational proposal.

\section{Keywords}

Fractions Teaching; Pre-algebra; Basic Education 


\section{Sumário}

1Introdução.

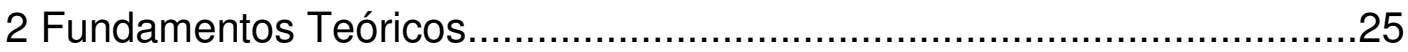

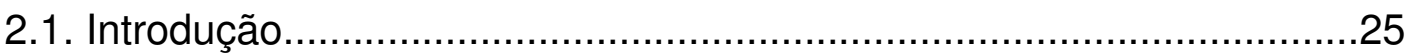

2.2. Dificuldades na Aprendizagem de Frações ..................................27

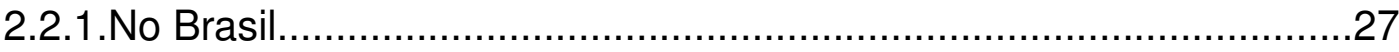

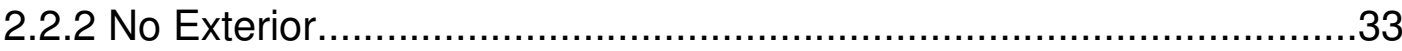

2.2.2.1 Os Resultados sobre Frações no Programa CSMS ........................35

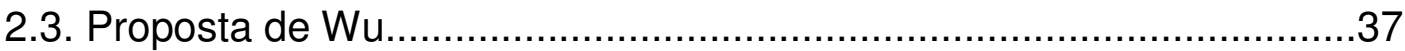

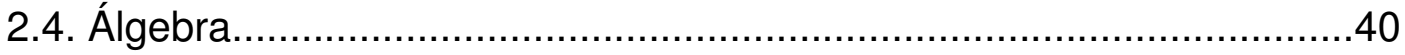

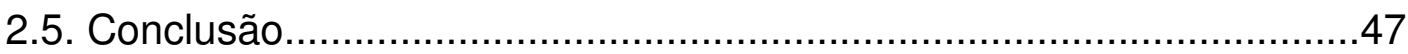

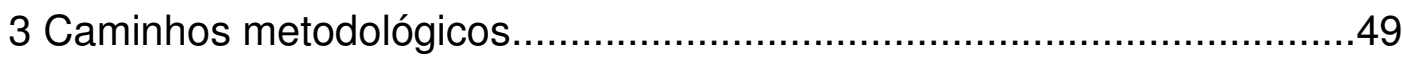

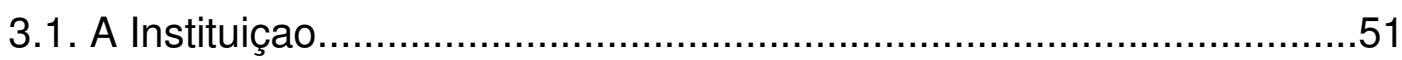

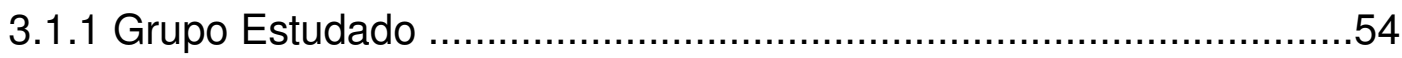

3.2 Instrumento para comparação: sobre o começar e o terminar.............55

3.2.1 Origem - época do instrumento: a que ele se propõe .......................55

3.2.2 Retomada da Avaliação em 2007 ............................................57

3.3 Instrumentos de coleta de dados da proposta................................57

3.4 Procedimentos da realização da proposta.....................................58

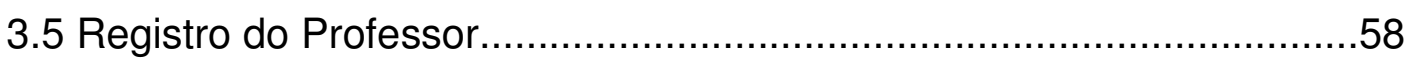

4 Procedimentos Didáticos Implementados e seua evolução....................59

5.Análise comparativa dos Testes Diagnósticos: principais constatações sobre o desempenho................................................93

5.1 Análise da Primeira Questão...................................................93

5.2 Análise da Segunda Questão................................................100

5.2 Análise da Terceira Questão.....................................................104

5.4 Análise da Quarta Questão ......................................................108 


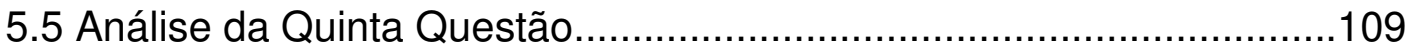

5.6 Análise da Sexta Questão.............................................................114

6 Análise e Resultados do Experimento em 2006................................120

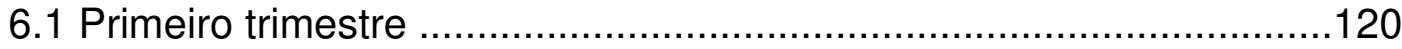

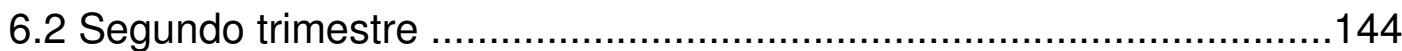

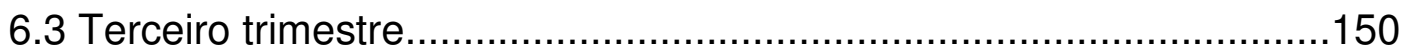

7 Análise da proposta pelos resultados em 2007 ..................................177

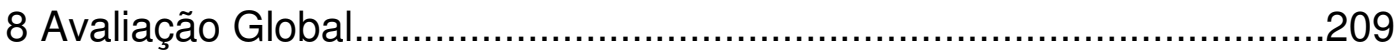

8.1 Análise da Evolução do Desempenho do aluno.................................209

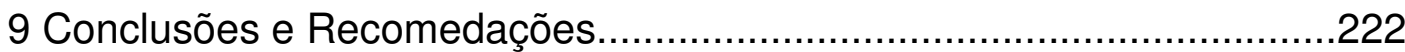

9.1 Recomendações para Projetos Futuros...........................................224

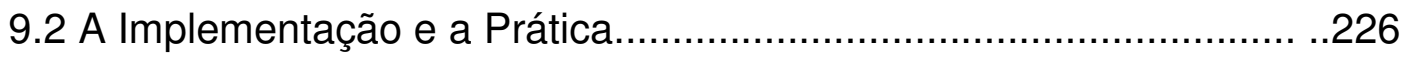

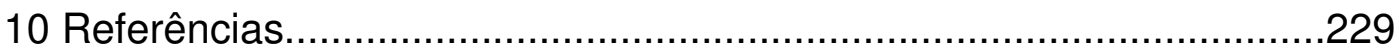

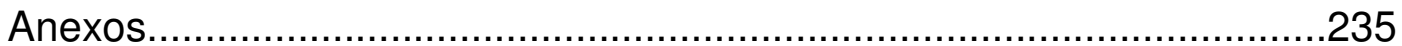




\section{Lista de figuras}

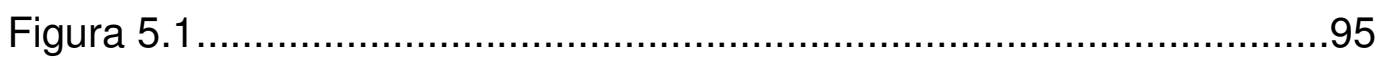

Figura 5.2

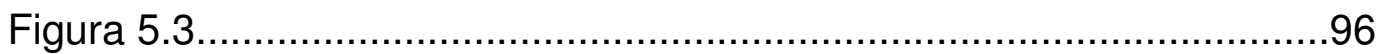

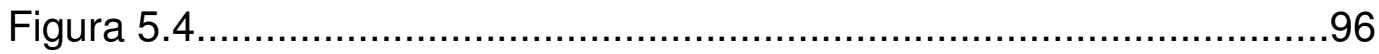

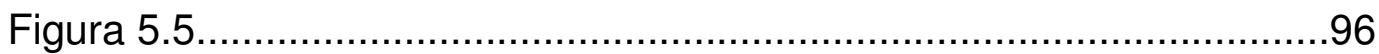

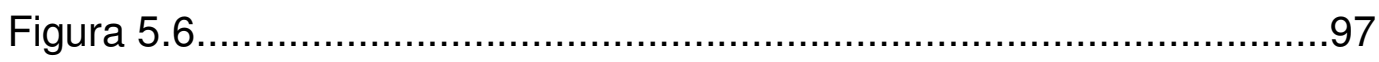

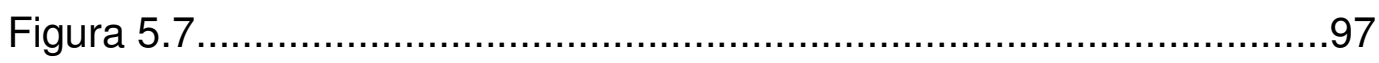

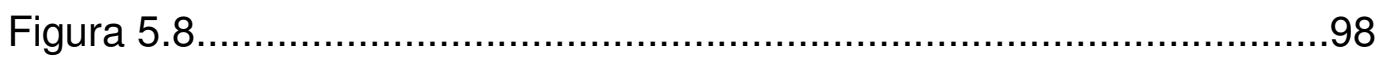

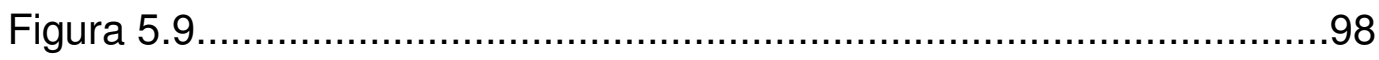

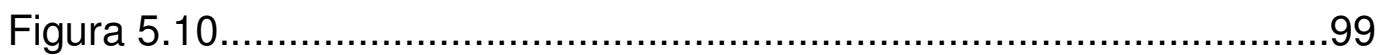

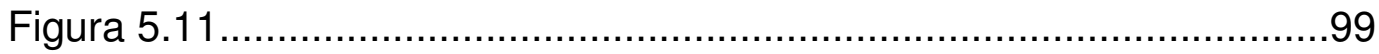

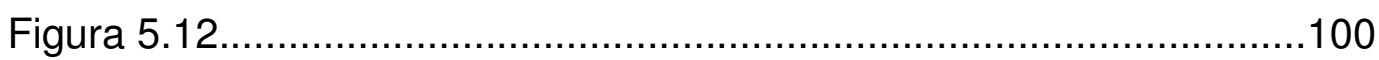

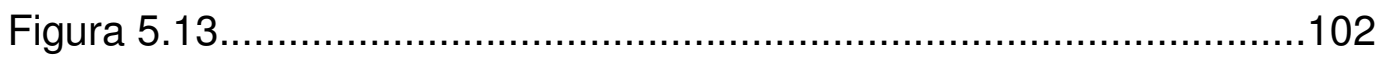

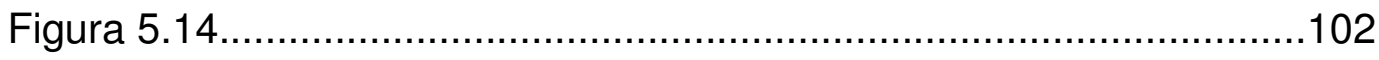

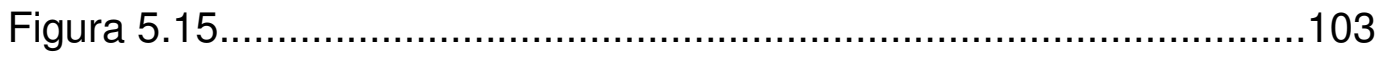

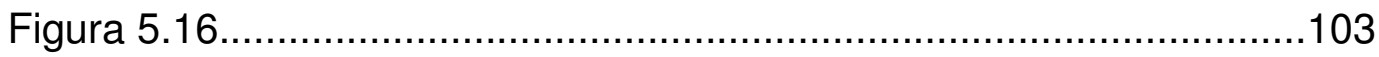

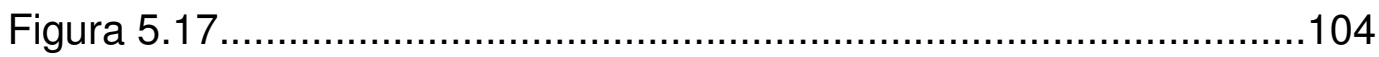

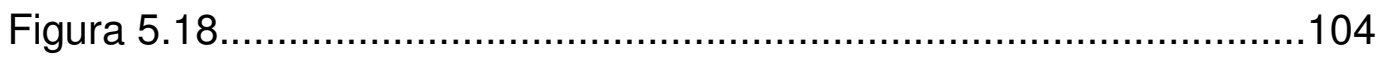

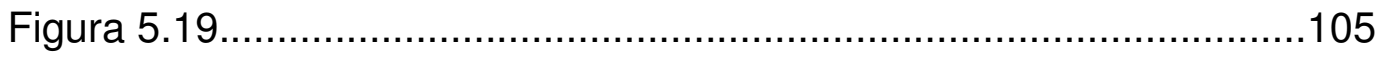

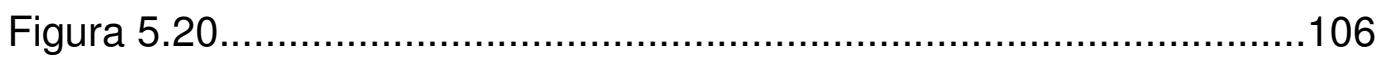

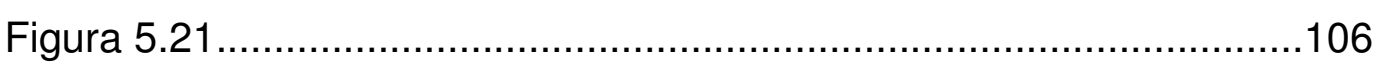

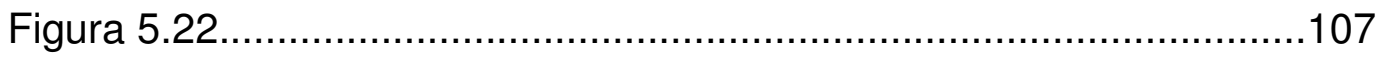

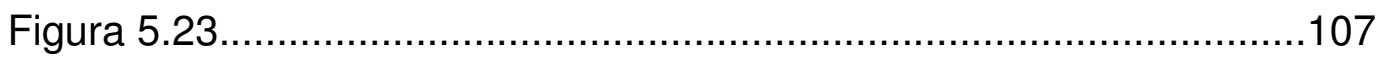

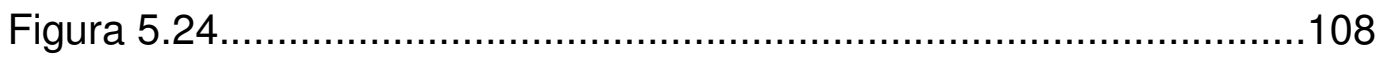

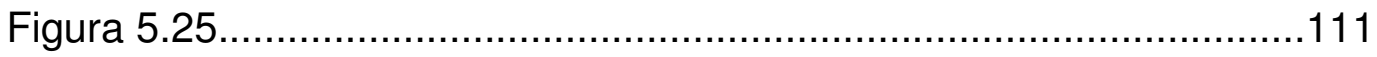

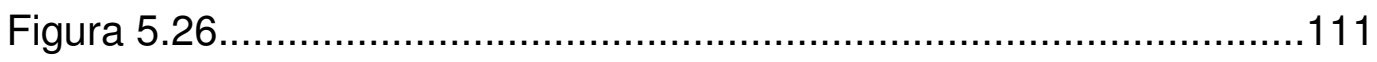

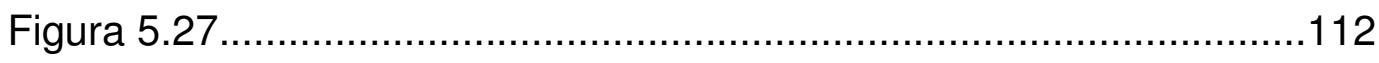

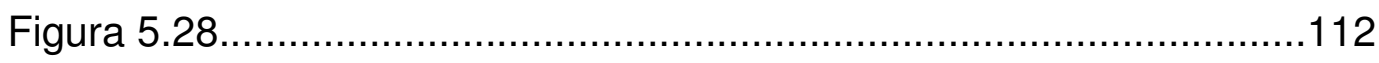

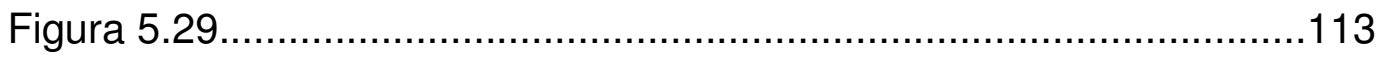

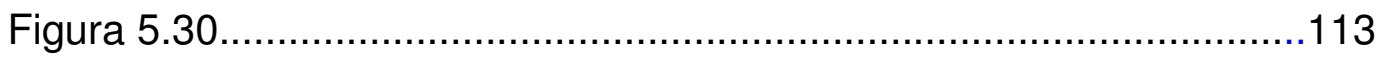




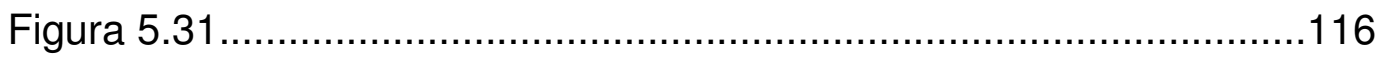

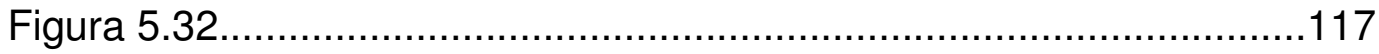

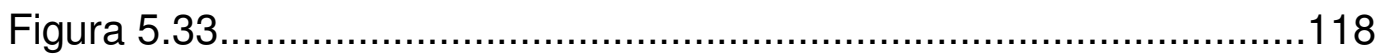

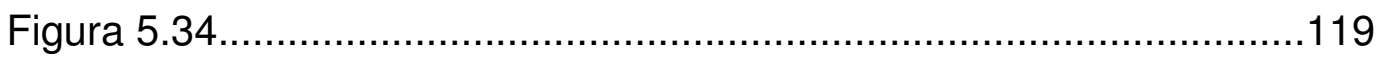

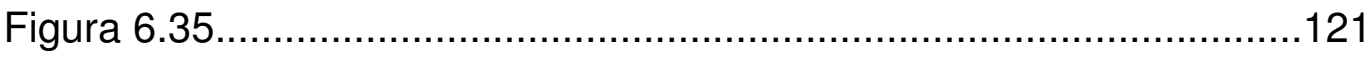

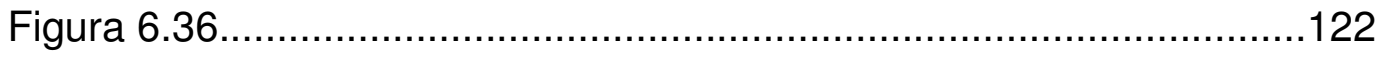

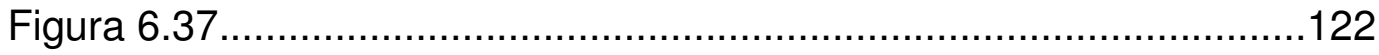

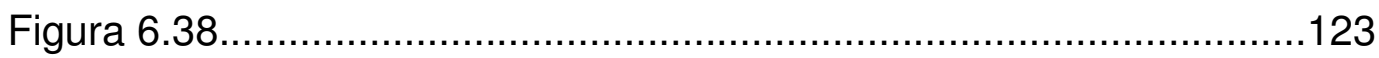

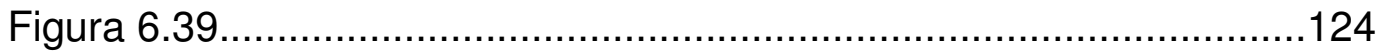

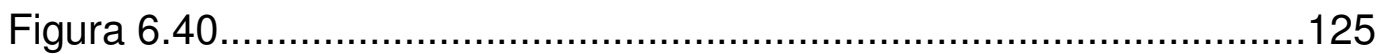

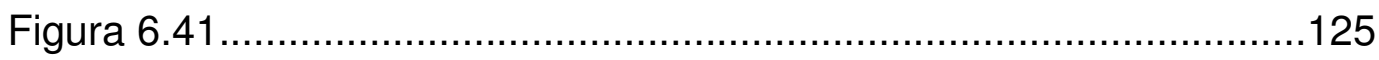

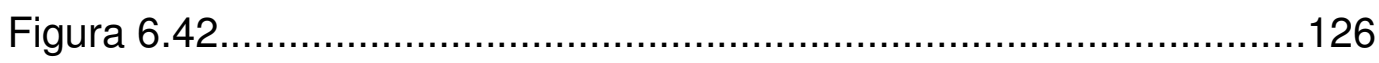

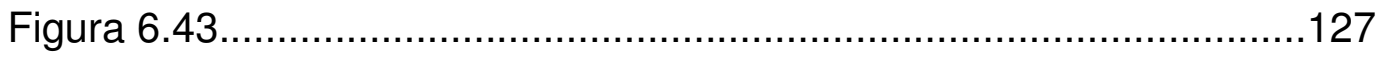

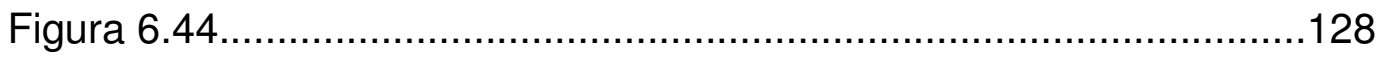

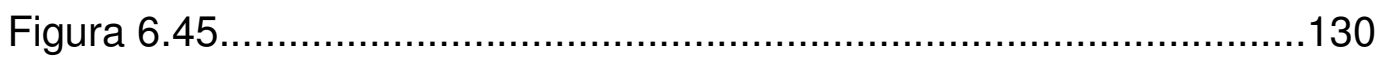

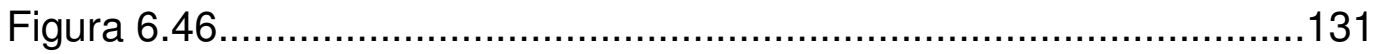

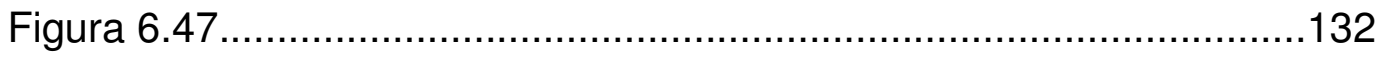

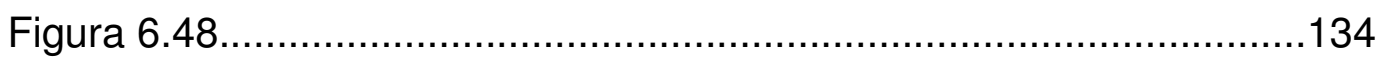

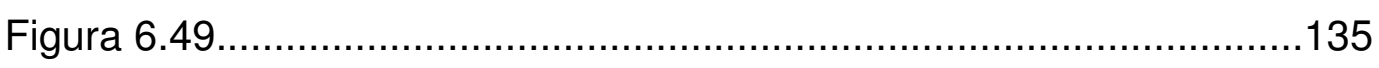

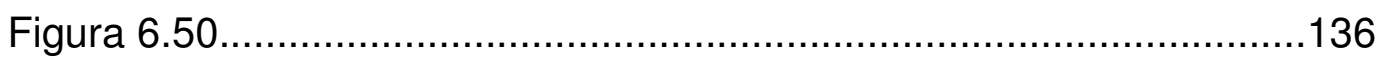

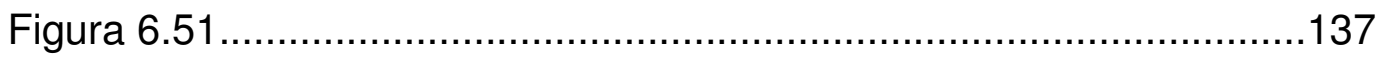

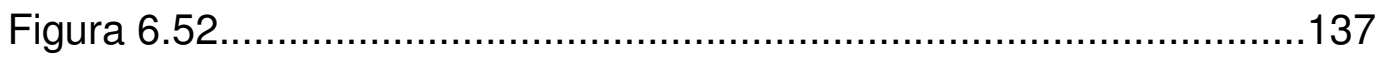

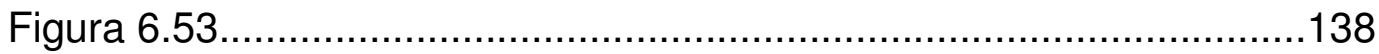

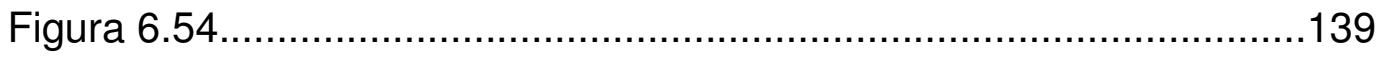

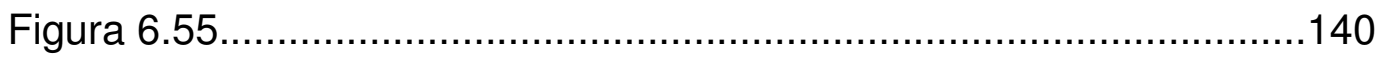

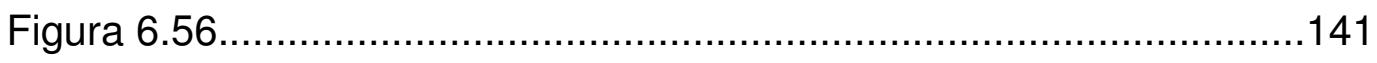

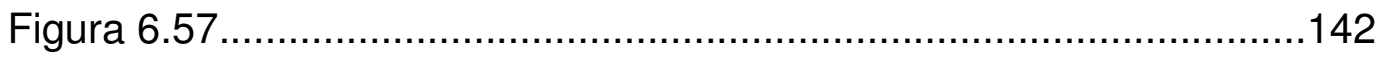

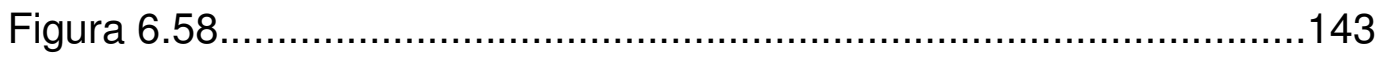

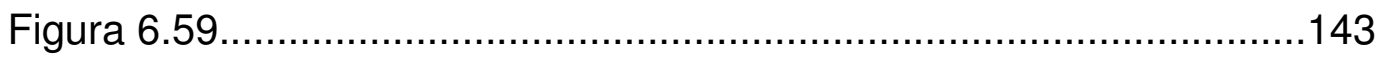

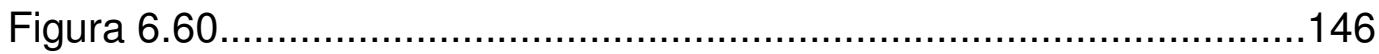

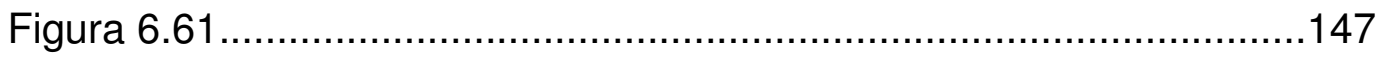

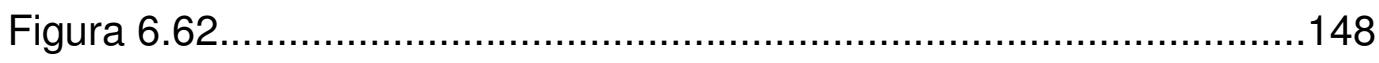

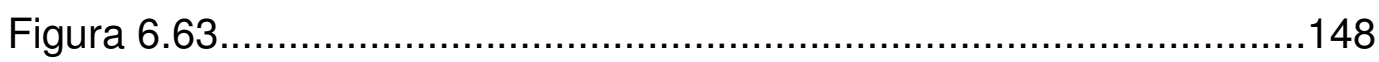




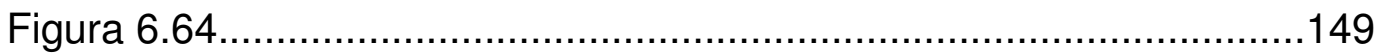

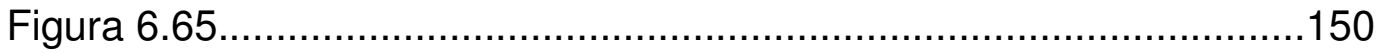

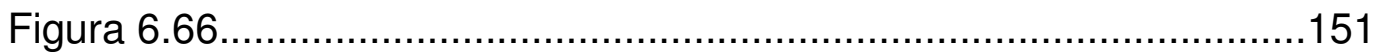

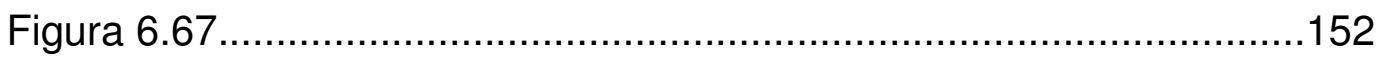

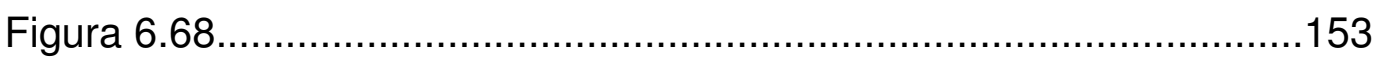

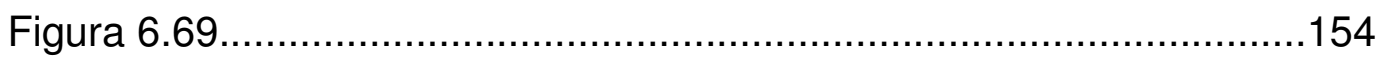

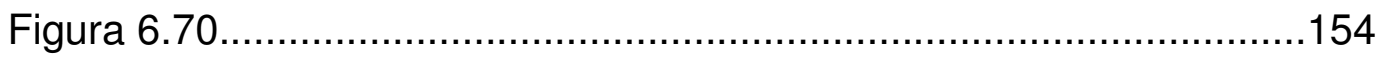

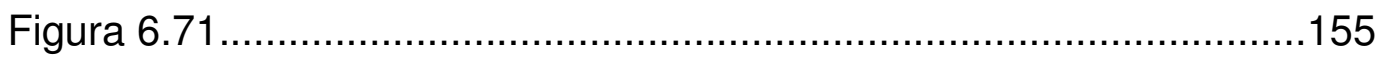

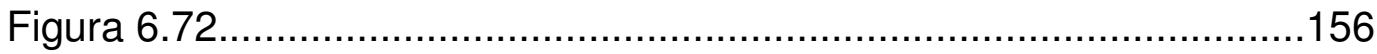

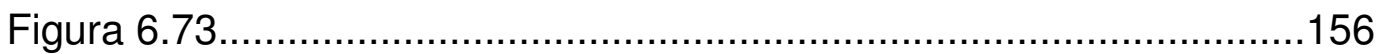

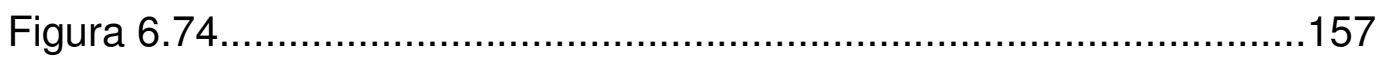

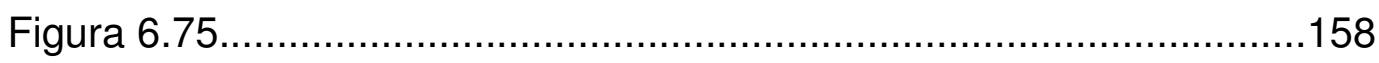

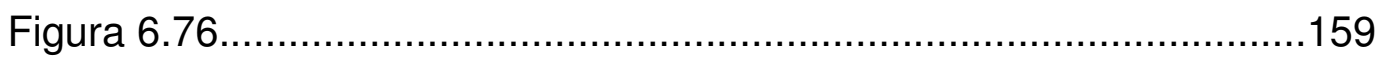

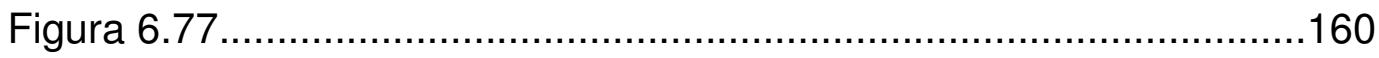

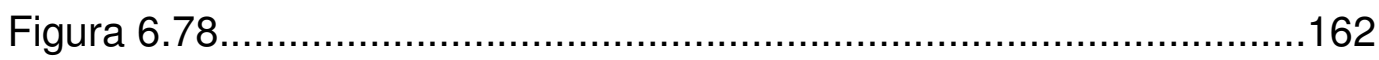

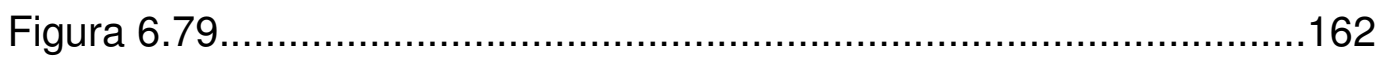

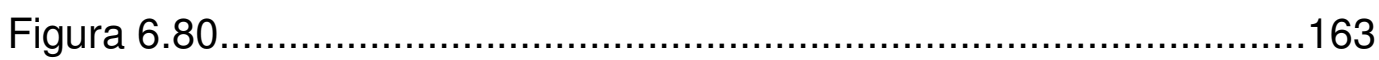

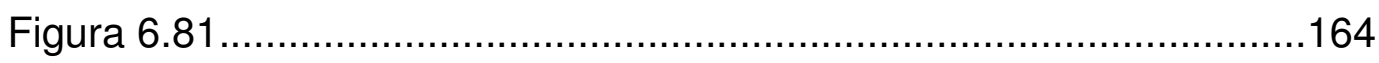

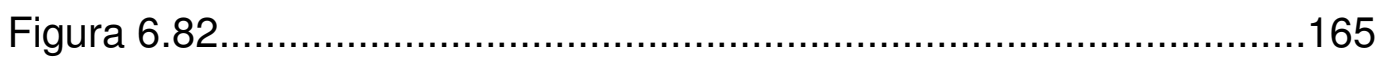

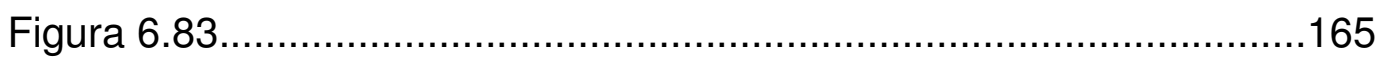

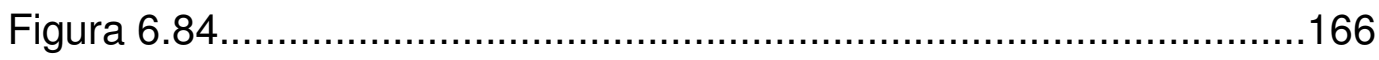

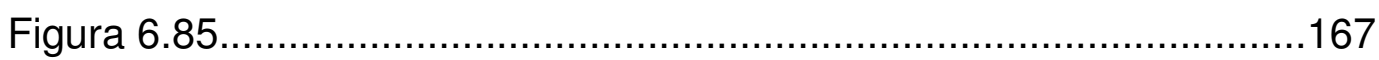

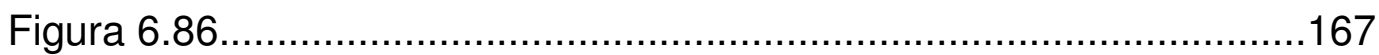

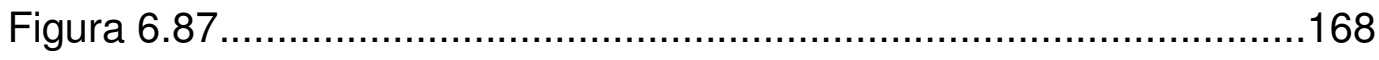

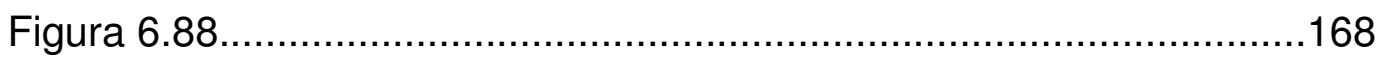

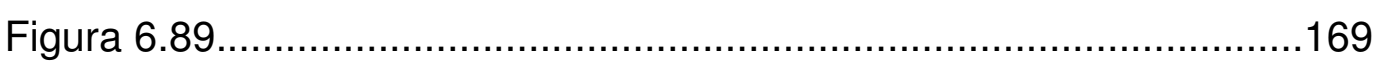

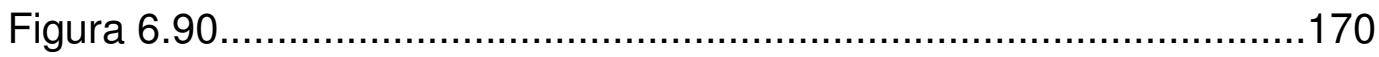

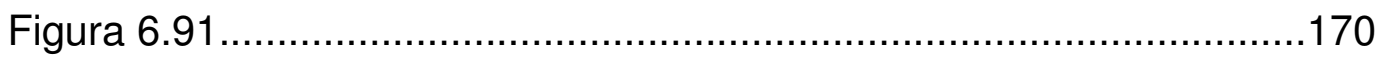

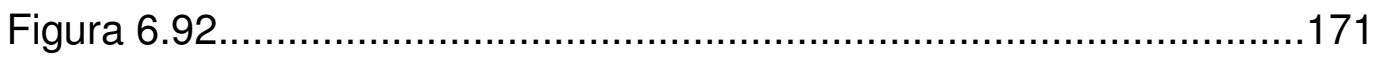

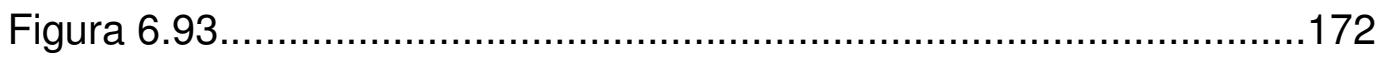

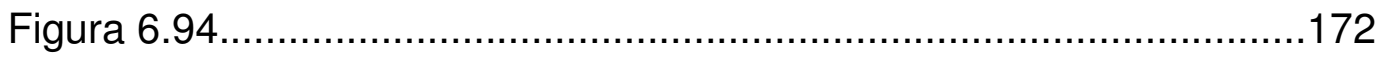

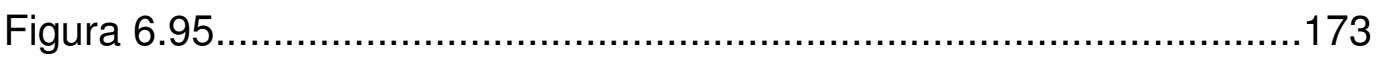

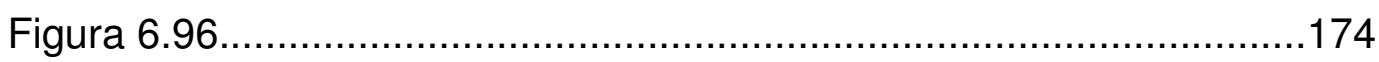




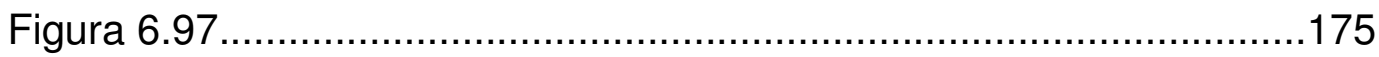

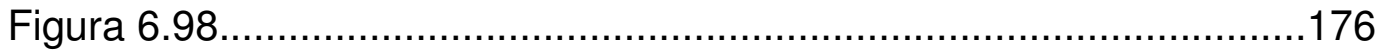

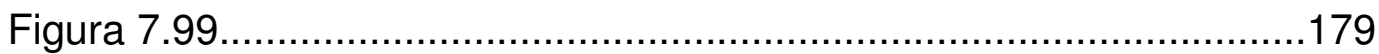

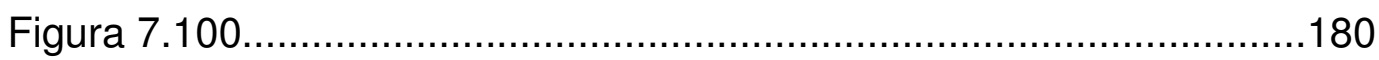

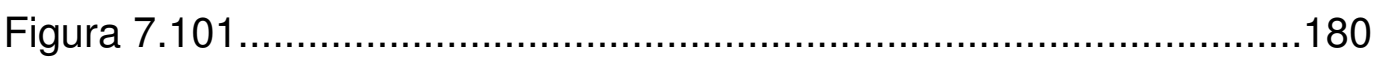

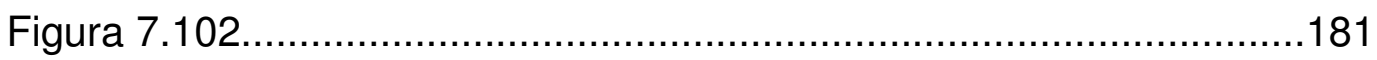

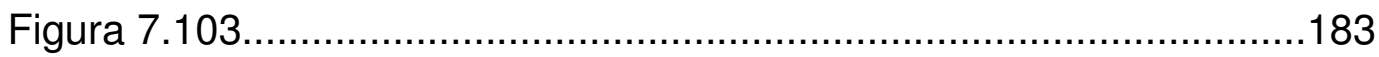

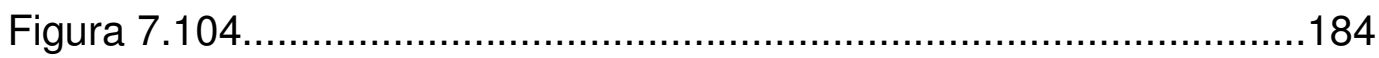

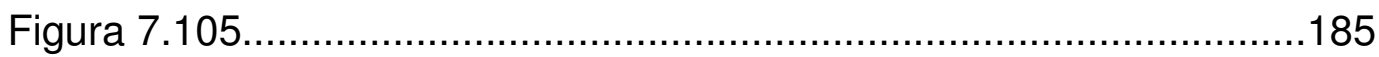

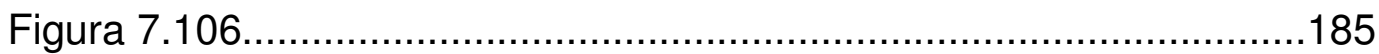

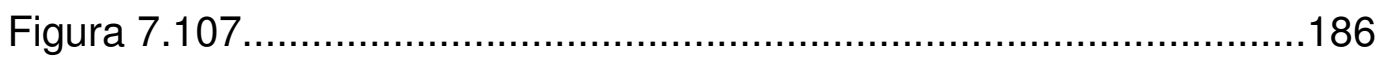

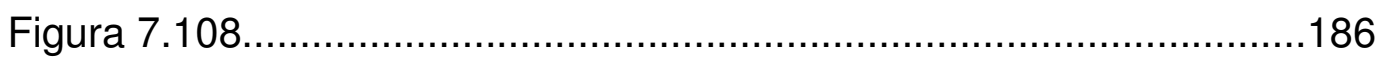

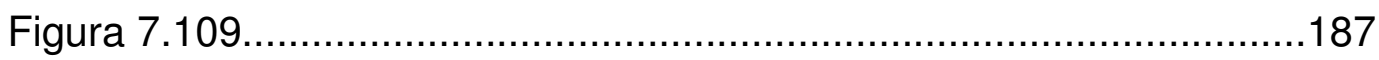

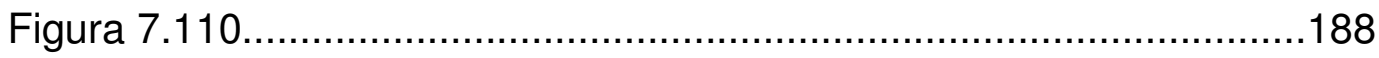

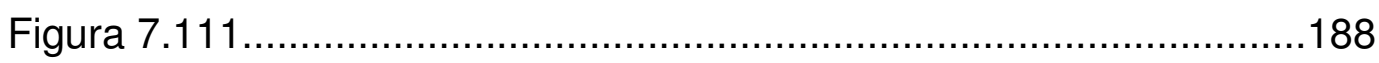

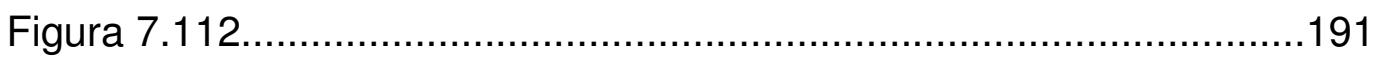

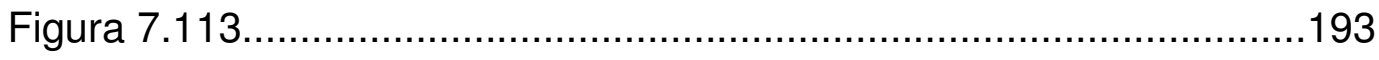

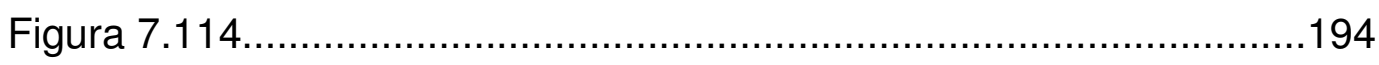

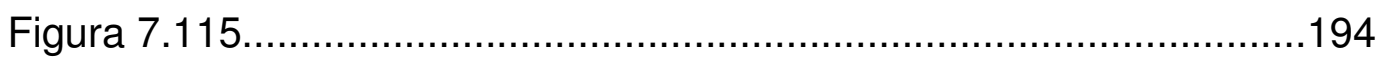

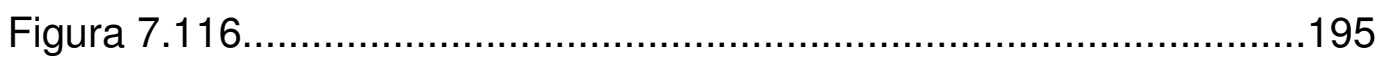

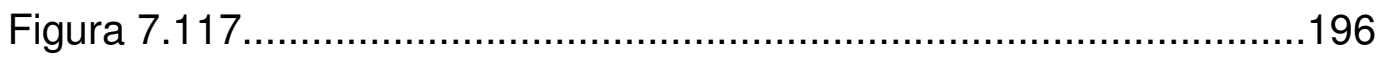

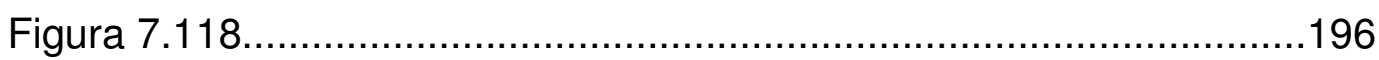

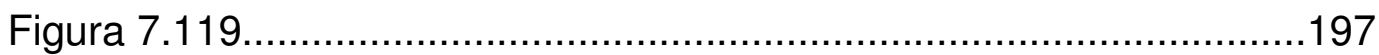

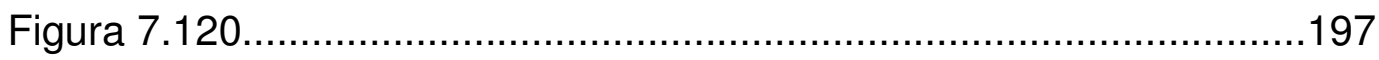

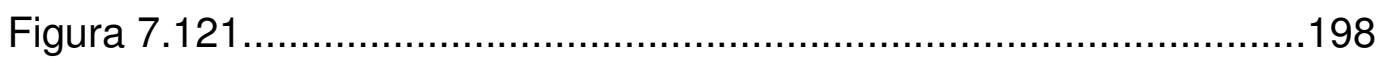

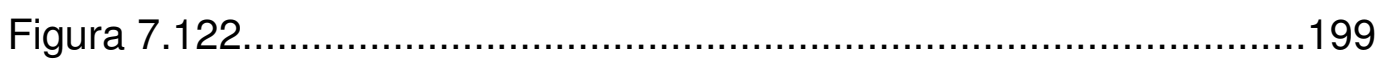

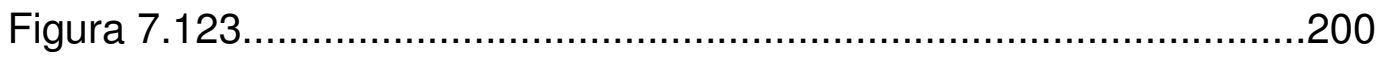




\section{Lista de quadros e gráficos}

Quadro 3.1: Modificações das questões do $1^{\circ}$ e $2^{\circ}$ teste diagnóstico.....56

Quadro 4.1:Conteúdos programáticos da 6⿳⺈ série (turma 604)

da Unidade Escolar Centro. .59

Quadro 4.2: Conteúdos programáticos da 6⿳⺈ série da Unidade

Escolar Centro (demais turmas).

Quadro 4.3: Conteúdos programáticos da $8^{\circ}$ ano da Unidade

Escolar Centro $(801,803$ e 805).

Quadro 5.1:Resultados relativos à $1^{\text {a }}$ questão do teste diagnóstico.......94

Quadro 5.2:Resultados relativos à $2^{\text {a }}$ questão do teste diagnóstico.....101

Quadro 5.3:Resultados relativos à $3^{\mathrm{a}}$ questão do teste diagnóstico.....105

Quadro 5.4:Resultados relativos à $3^{\mathrm{a}}$ questão do teste diagnóstico examinado a luz do erro mais frequente.

Quadro 5.5:Resultados relativos à $4^{\mathrm{a}}$ questão do teste diagnóstico.....109

Quadro 5.6: Resultados relativos à $5^{\mathfrak{a}}$ questão do teste diagnóstico....110

Quadro 5.7:Resultados relativos à $6^{\mathrm{a}}$ questão do teste diagnóstico.....115

Quadro 6.1:Desempenho dos alunos - 1 o teste individual 12/05...........120

Quadro 6.2:Desempenho dos alunos - 1ㄹ. Prova Trimestral 21/07 .........133

Quadro 6.3:Desempenho dos alunos no final do $2^{\circ}$ trimestre .................144

Quadro 6.4:Desempenho dos alunos - 2 ${ }^{\text {a }}$ Prova Trimestral 22/09.........144

Quadro 6.5:Desempenho dos alunos $-1^{\circ}$ teste individual 3otrimestre....150

Quadro 6.6:Desempenho dos alunos - Prova Única ............................161

Quadro 7.1:Desempenho dos alunos - na $5^{\text {a }}$ questão ..........................178

Quadro 7.2:Desempenho dos alunos - na 6 questão............................179

Quadro 7.3:Desempenho dos alunos - na $7^{\mathrm{a}}$ e $8^{\mathrm{a}}$ atividade....................182

Quadro 7.4:Desempenho dos alunos - na $3^{\mathrm{a}}$ questão - $^{\mathrm{a}}$ atividade........184

Quadro 7.5:Desempenho dos alunos - na $2^{\mathrm{a}}$ questão-8a atividade..........186

Quadro 7.6:Desempenho dos alunos - na $3^{\text {a }}$ questão- $8^{\text {a }}$ atividade.........187

Quadro 7.7:Desempenho dos alunos - na $4^{\mathrm{a}}$ questão- $8^{\mathrm{a}}$ atividade........189

Quadro 7.8:Desempenho dos alunos - Prova única de 2007.................192

Quadro 7.9:Desempenho dos alunos - Prova de Avaliaçao Final..........200 
Quadro 8.1:Origem dos alunos da turma da turma $604 \ldots \ldots \ldots \ldots \ldots \ldots \ldots . . .210$

Quadro 8.2:Desempemho final das turmas da $5^{\underline{a}}$ série de $2005 \ldots \ldots \ldots \ldots . .211$

Quadro 8.3:Dempenho da $1^{\text {a }}$ certificação de 2006 .............................212

Quadro 8.4: Dempenho da $2^{\mathrm{a}}$ certificação de 2006 .............................213

Quadro 8.5: Dempenho da 3ª certificação de 2006..............................213

Quadro 8.6: Dempenho final da 6⿳亠丷a série de 2006..............................214

Quadro 8.7: Médias do $1^{\circ}$ trimestre de 2006......................................215

Quadro 8.8: Médias do 20 trimestre de 2006 .....................................216

Quadro 8.9: Médias do 3o trimestre de 2006........................................216

Quadro 8.10: Médias finais do ano letivo de 2006............................217

Gráfico 8.1:Comparação entre o desempenho do $1^{\circ}$ trimestre da turma 803: antigos alunos da $604 \times$ novos alunos.............................217

Gráfico 8.2:Comparação entre o desempenho do $2^{\circ}$ trimestre da turma 803: antigos alunos da $604 \mathrm{x}$ novos alunos................................218

Gráfico 8.3: Comparação entre o desempenho do 3 o trimestre da turma 803: antigos alunos da $604 \mathrm{x}$ novos alunos ...............................219

Gráfico 8.4: Comparação entre o desempenho anual da turma 803: antigos alunos da $604 \times$ novos alunos .219

Gráfico 8.5: Comparação entre o desempenho final da turma 803: antigos alunos da $604 \mathrm{x}$ novos alunos 


\section{Lista de anexos}

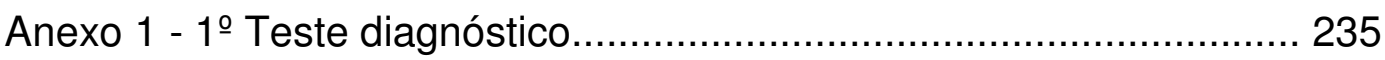

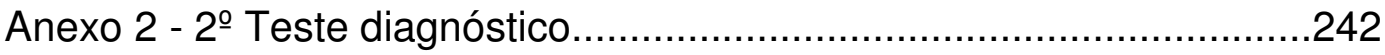

Anexo 3 - Definição de fração segundo Wu:

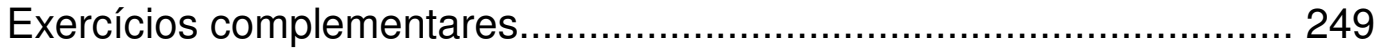

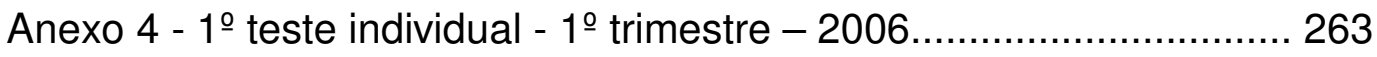

Anexo 5 - Lista de exercícios de apoio - junho - 2006........................ 271

Anexo 6 - Lista de Exercícios - julho - 2006......................................... 281

Anexo 7 - Prova da 1a certificação - julho - 2006.................................289

Anexo 8 - Prova da 2ª certificação - setembro - 2006............................294

Anexo 9 - Teste individual - 3 o trimestre - outubro - 2006.....................301

Anexo 10 - Prova Única - dezembro - 2006.........................................309

Anexo 11 - Prova Avaliação Final (PAF) - 2006................................. 313

Anexo 12 - Atividades $7^{\text {a }}-8^{\text {a }}$ atividades - 2007:

Reta Numérica - Expressões Algébricas 2007........................................

Anexo 13 - Calendários Escolares - 2006 -2007..................................322

Anexo 14 - Relação de Conteúdos - Gráficos - 2006 -2007.....................325 